\title{
Características de una línea celular de crecimiento continuo de Aedes taeniorhynchus (Diptera: Culicidae)
}

\author{
Felio J. Bello ${ }^{1}$, Jaime A. Rodríguez ${ }^{2}$, Jorge Boshell ${ }^{3}$, \\ Víctor A. Olano ${ }^{4}$, Alberto Morales ${ }^{5}$, Gloria Rey ${ }^{6}$, William Ramírez ${ }^{2}$
}

\begin{abstract}
Resumen
Se estableció una nueva línea celular, LSB-AT0793, a partir de tejidos embrionarios del mosquito Aedes taeniorhynchus. El primer subcultivo se inició en julio de 1993 y hasta la fecha, octubre de 1995, se han efectuado 360 pases. El medio de cultivo utilizado para el crecimiento y mantenimiento de las células fue MM/VP12, con un pH de 6,8 y una temperatura promedio de $28^{\circ} \mathrm{C}$. La mayoría de las células en las monocapas confluentes fueron de formas epitelioides. Se reconocieron las características del cariotipo de la especie y se establecieron los patrones de bandas C y G. Se determinaron los perfiles isoenzimáticos de la línea celular, utilizando cuatro sistemas diferentes: PGI, PGM, MPI y 6-PGDH, los cuales coincidieron con los patrones obtenidos a partir de extractos de pupas de la especie. También, se compararon los perfiles isoenzimáticos de la presente línea celular con los de Anopheles albimanus y con los del clon C6/36. Se demostró que las células están libres de bacterias y hongos. Se estandarizó la técnica de congelación en nitrógeno líquido en donde se mantienen varios subcultivos en diferentes pases.
\end{abstract}

\section{Summary}

A new cell line was established, LSB-AT793, from the embryonic tissues of the mosquito Aedes taeniorhynchus. The first subculture was iniciated in July 1993. Up to the present, October 1995, 360 passages have been performed. The culture media used for cell growth and maintenance was MM/VP12, with a pH of 6.8 and a temperature of $28^{\circ} \mathrm{C}$. The majority of cells in the confluent monolayers were epithelial-like. The characteristics of the karyotype species were recognized and the $\mathrm{G}$ and $\mathrm{C}$-banding patterns were established. Also, the isoenzyme profiles of the cell line, using four differents systems, PGI, PGM, MPI and 6-PGDH, were determined which coincide with the isoenzyme patterns derived from pupae extracts. The isoenzyme profiles of this cell line was compared with the isoenzyme phenotype of Anopheles albimanus and with the clone C6/36. It was shown that cells are free of bacteria and fungi. The frozen technique in liquid nitrogen was standarized. This technique has allowed the storage of a variety of subcultures in different passages.

\footnotetext{
1. M.Sc., Investigador, Departamento de Química y Biología, Universidad de La Salle.

2. Estudiantes de pregrado, Universidad de La Salle.

3. Médico, Laboratorio de Virología, INS.

4. Biólogo, Laboratorio de Entomología, INS.

5. M.Sc., Laboratorio de Entomología, INS.

6. Bacterióloga, Laboratorio de Virología, INS.
} 
Ae. taeniorhynchus es un mosquito de interés médico-veterinario por ser eficiente vector del virus de la encefalitis equina venezolana tipo epidemo-epizoótico (1). En Colombia, en el departamento de La Guajira, durante los meses de septiembre y octubre de 1995 se registró una epidemia de la enfermedad, la cual, según informes del Ministerio de Salud ocasionó la muerte a 26 personas. Esta especie ha sido incriminada como uno de los vectores más abundantes en la zona que, por evidencia epidemiológica, estaría vinculada en la transmisión de la patología mencionada (2).

Los cultivos de tejidos fueron ideados a comienzos del siglo por Harrison en 1907 (3) y Carrel en 1912 (4) como un método para estudiar el comportamiento de las células animales libres de variaciones sistémicas que pudieran surgir en el animal durante el proceso normal de homeóstasis y bajo la presión de un experimento. La técnica fue elaborada primero con fragmentos disgregados del tejido y el crecimiento fue restringido a la migración de células con ocasionales mitosis en el crecimiento. A partir de los años 50 fue empleada la técnica de cultivos de células, que sustituye a los tejidos, y se refiere a los cultivos derivados de células dispersas que son tomadas de un tejido original, de un cultivo primario o de una línea celular o cepa celular mediante la disgregación enzimática, mecánica o química (5).

Los cultivos celulares de mosquitos se inician a partir de explantes de tejidos embrionarios, de larvas neonatas y gónadas, cuyas células después de frecuentes pases o subcultivos se van transformando hasta lograr una persistencia indefinida lo cual caracteriza a una línea celular de crecimiento continuo (6). En la iniciación de cultivos celulares de insectos se trabajó mucho antes de 1966 (Ball, 1954 (7), Beckell, 1956 (8) y Kitamura, 1965 (9), entre otros) hasta que, en este año, Grace (10) obtuvo la primera línea celular a partir de tejidos larvarios de Ae. aegypti; desde entonces diversas líneas celulares de insectos se han establecido, correspondiendo principalmente a los órdenes: díptera, lepidóptera, homóptera, hemíptera y ortóptera $(11,12)$. En 1995, Bello et al. (13) reportaron los cultivos celulares primarios de Ae. taeniorhynchus y describieron sus características más notables.

Los cultivos celulares de insectos se consideran una técnica útil para estudios fundamentales de fisiología celular, genética y bioquímica e igualmente son empleados como sustratos en el estudio de parásitos, para aislar e identificar arbovirus, en estudios de resistencia a insecticidas, para preparar antígenos, en estudios básicos de ciclos biológicos y en la producción de virus recombinados que se utilizan en control biológico $(6,11-12,14$ 18).

En el presente trabajo se reporta por primera vez las características de crecimiento, morfológicas, citogenéticas y de perfiles isoenzimáticos de una línea celular de $A e$. taeniorhynchus

\section{Materiales y métodos}

Cultivos celulares primarios. Se obtuvieron de huevos embrionados de acuerdo con el procedimiento descrito para esta especie por Bello et al. en 1995 (13). Previa esterilización, los huevos fueron macerados y finalmente explantados en el medio de crecimiento seleccionado.

Subcultivos. El primer subcultivo se realizó el 14 de julio de 1993 a partir del cual las células se han mantenido subcultivando por más de tres años. El desprendimiento de las monocapas confluentes en los cultivos se realizaron mecánicamente con la ayuda de un policía de goma. Después de remover la monocapa y pipetear vigorosamente los contenidos celulares, se transfirieron los volúmenes seleccionados a frascos plásticos de $25 \mathrm{~cm}^{2}$ y a frascos de vidrio de 2 onzas, los cuales contenían 5.0 y $2.0 \mathrm{~mL}$ de medio de cultivo fresco, respectivamente. Los primeros subcultivos fueron realizados en proporciones de 1:2 a un intervalo de 6 días; luego, se incrementaron gradualmente hasta alcanzar niveles de 1:10 con un tiempo promedio de incubación de tres días. El medio de cultivo empleado fue MM/VP12 $(19,20)$, suplementado con suero fetal bovino al $20 \%$ en los primeros 10 subcultivos; antibióticos (mez- 
cla de penicilina $100 \mathrm{u} / \mathrm{mL}$ y estreptomicina 100 $\mathrm{u} / \mathrm{mL}$ ) y amfotericina $B$ en concentraciones de $50 \mathrm{u} / \mathrm{mL}$. Finalmente, los frascos de cultivos se incubaron a una temperatura de $28^{\circ} \mathrm{C}$ y diariamente se efectuó la observación con un microscopio invertido marca Olimpus CK-2 $(16,18)$.

Pruebas de esterilidad. En el desarrollo del proceso para lograr la línea celular, a los cultivos en forma periódica (cada cinco meses) se le efectuaron pruebas de esterilidad para descartar contaminación con bacterias y hongos. Para tal efecto, se tomaron dos gotas del medio de cultivo con células suspendidas y se adicionaron a tubos con medios de infusión cerebrocorazón y medios de Sabouraud, los cuales se incubaron a $36^{\circ} \mathrm{C}$ y temperatura ambiente respectivamente por un tiempo de una semana para los primeros y 15 días para los tubos con medio Sabouraud $(21,22)$.

Congelación. El medio de congelación se preparó con $50 \%$ de medio MM/VP12, $40 \%$ de suero fetal bovino y $10 \%$ de dimetil-sulfóxido; las células se resuspendieron en éste y los viales con $1,5 \mathrm{~mL}$ de suspensión celular se llevaron a refrigeración a $5^{\circ} \mathrm{C}$ por 10 minutos, luego a congelación a $-70^{\circ} \mathrm{C}$ por cuatro horas y, finalmente, a nitrógeno líquido. También se evaluó la técnica de congelación rápida con vapores en hielo seco antes de guardarse en los tanques de nitrógeno líquido (21).

Características morfológicas. La morfología de las células fue descrita y fotografiada a partir de la observación de los cultivos, empleando para tal efecto un microscopio invertido con contraste de fases y con sistema microfotográfico marca Leitz, en aumentos de 100 a 400X.

Características citogenéticas.Los cromosomas se prepararon de acuerdo con la técnica de Schneider (23).

Bandas C. Láminas en blanco de cuatro días de maduración se sumergieron en ácido clorhídrico $0,2 \mathrm{~N}$ por 50 minutos; se lavaron en agua corriente y se colocaron en hidróxido de bario al $5 \%$ por 1 minuto a $53^{\circ} \mathrm{C}$; posteriormente, se incubaron a $54^{\circ} \mathrm{C}$ en solución doblemente citratada ( $2 \times$ SSC) por una hora. La tinción se efectuó con Giemsa al $2 \%$ (24).

Bandas G. Láminas en blanco de 10 días de maduración se sumergieron durante 30 minutos en solución doblemente citratada ( 2 x SSC) a $52^{\circ} \mathrm{C}$; previo enjuague en agua corriente, se colocaron por 10 segundos en tripsina a $9^{\circ} \mathrm{C}$, cuya acción se detuvo con etanol al $70 \%$. La tinción se realizó con Giemsa al 2\%. Se seleccionaron las mejores metafases utilizando esta técnica (25).

Perfiles isoenzimáticos. Los fenotipos isoenzimáticos de cuatro sistemas fueron examinados: fosfoglucosa isomerasa (PGI-5.3.1.9), fosfoglucomutasa (PGM-2.7.5.1), manosa fosfato isomerasa (MPI-5.3.1.8.) y 6-fosfogluconato dehidrogenasa (6-PGDH-1.1.1.4.4.). Las isoenzimas se separaron mediante la técnica de electroforésis en acetato de celulosa, de acuerdo con el procedimiento descrito por Brown y Knudson (26). Las muestras celulares se corrieron simultáneamente con extractos de pupas procedentes de la colonia de $A e$. taeniorhynchus, cepa Barranquilla, Colombia (27); también se compararon los perfiles isoenzimáticos de las líneas celulares de $A e$. taeniorhynchus y An. albimanus con los patrones de la cepa C6/36.

A todas las muestras se les adicionó buffer celular correspondiente a cada sistema, luego se congelaron y descongelaron tres veces consecutivas (nitrógeno líquido y temperatura ambiente) para, posteriormente, centrifugar a 1000 g por 10 minutos la suspensión celular, el sobrenadante fue tomado para las siembras respectivas sobre las membranas de acetato de celulosa, utilizando para tal efecto el aplicador Zip-Zone (Helena Laboratories, Beaumont, TX).

\section{Resultados}

Establecimiento de la línea celular. Un registro de los 360 pases efectuados durante $39 \mathrm{me}$ ses se muestran en la figura 1. En el primer mes, después de obtenidos los cultivos primarios, las células crecieron lentamente y el doble de la población celular se alcanzó en un tiempo 


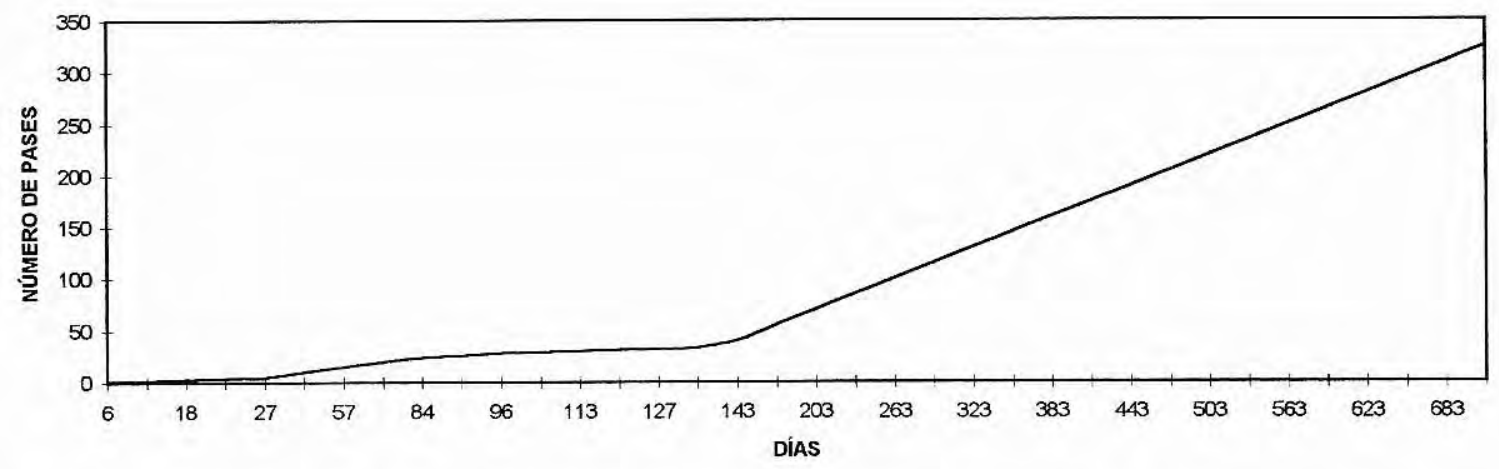

Figura 1. Registro de los pases efectuados a los cultivos celulares de Ae. taeniorhynchus.

promedio de 20 horas. El crecimiento de las células se produjo en forma de monocapa y éstas se adhirieron firmemente a la superficie del frasco. A partir del subcultivo número 35 en adelante, las células entraron en una fase de crecimiento continuo, resultando en el establecimiento de la primera línea celular de $A e$. taeniorhynchus, denominada LSB-AT0793 (figura 2). Las células han permanecido desde los explantes de tejidos embrionarios hasta el más alto número alcanzado de subcultivos en el medio MM/VP12, con variaciones en la concentración de suero fetal bovino, ya que del $20 \%$ en los primeros diez subcultivos, se empezó a reducir la concentración hasta llegar al $5 \%$ en pases superiores a 200 . El rango promedio del pH del medio fue de 6,8 y la temperatura óptima de incubación de las células fue de $28^{\circ} \mathrm{C}$.

Las células no evidenciaron contaminación con bacterias ni con hongos.

La viabilidad de las células congeladas se demostró a la primera semana y también después de dos años de permanecer en nitrógeno líquido. La descongelación se efectuó en forma rápida.

Características morfológicas. La gran mayoría de las células en la monocapa confluente fueron de tipo epitelioide, aunque se observaron aisladamente formas irregulares $y$, en algunos casos, células gigantes. A las 20 horas después de efectuados los subcultivos, las células en activa división fueron de apariencia fibroblástica (figura 3), especialmente cuando existieron espacios suficientes en la superficie de los frascos, en la medida en que aumentaron la densidad poblacional, las células se tornaron redondeadas o esféricas para finalmente adquirir la morfología característica del cultivo en la monocapa.

Características citogenéticas. En el cariotipo, obtenido a partir de células correspondientes a la línea establecida, el número diploide fue de 6 $(2 n=6)$, en donde el par 1 es el sexual, metacéntrico y los pares 2 y 3 fueron submetacéntricos y de mayor tamaño, confirmándose el reporte de Bello et al. (13) para esta especie. En menor proporción también se registraron tetraploidías (5\%).

En la figura 4 se observan los patrones de bandas $\mathrm{C}$, correspondientes a las regiones de heterocromatina constitutiva para cada uno de los cromosomas. Los promedios de la longitud de la banda, en relación a la longitud total de cada cromosoma fueron: par 1: 7,1\%; par 2: $4 \%$ y el par $3,5 \%$.

El patrón de bandas $\mathrm{G}$ se observa en la figura 5. Los promedios de bandas para cada par fueron: cromosoma 1: 6; para el cromosoma 2: 8 y para el cromosoma 3: 10. El idiograma de bandeamiento $\mathrm{G}$ se muestra en la figura 6 .

Perfiles isoenzimáticos. Los fenotipos isoenzimáticos de la línea celular establecida, correspondientes a los cuatro sistemas analizados fueron: 1 banda para PGI, PGM y 6-PGDH 


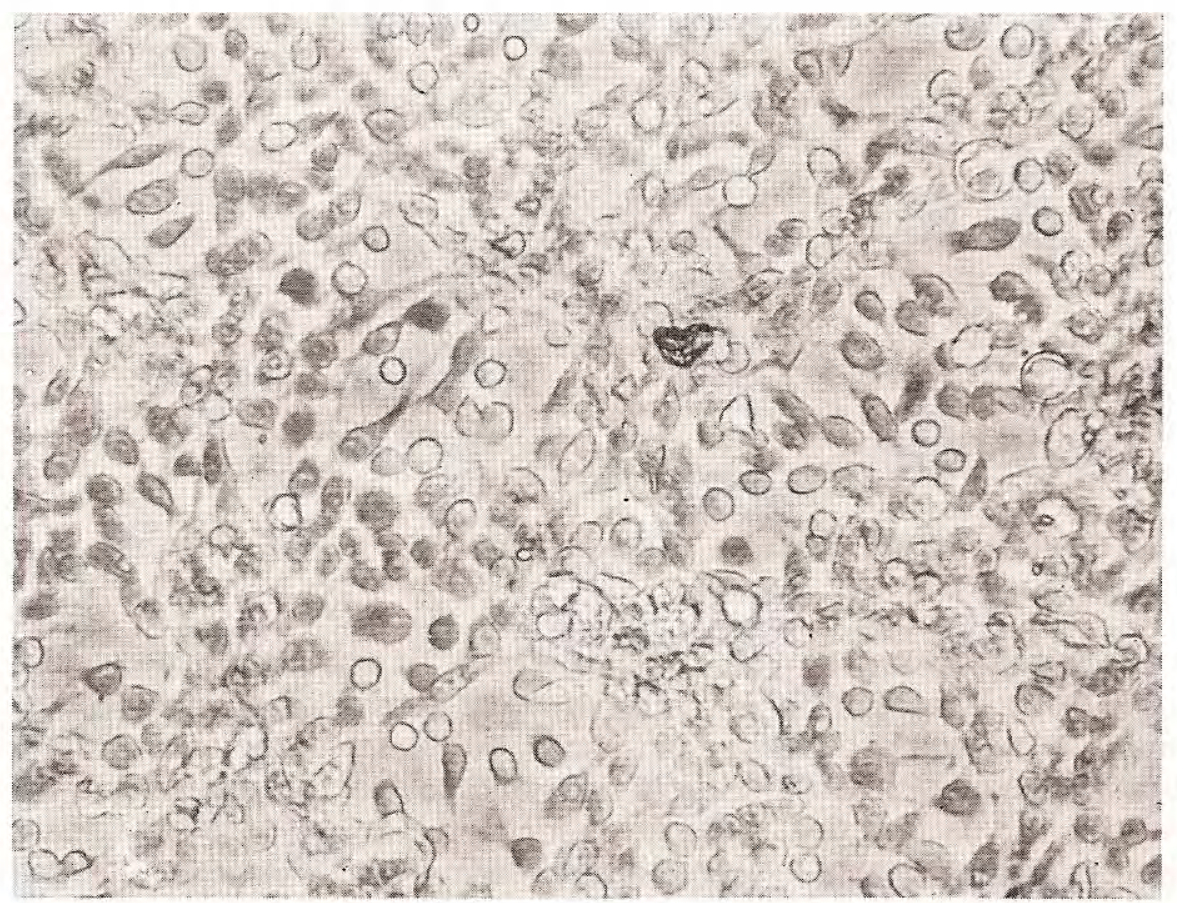

Figura 2. Monocapa confluente de la línea celular LSB-0793, correspondiente al subcultivo número 190.

Figura 3. Subcultivo celular de la línea LSB0793, pase 210 a las 20 horas después de la siembra con presencia de células fibroblásticas.

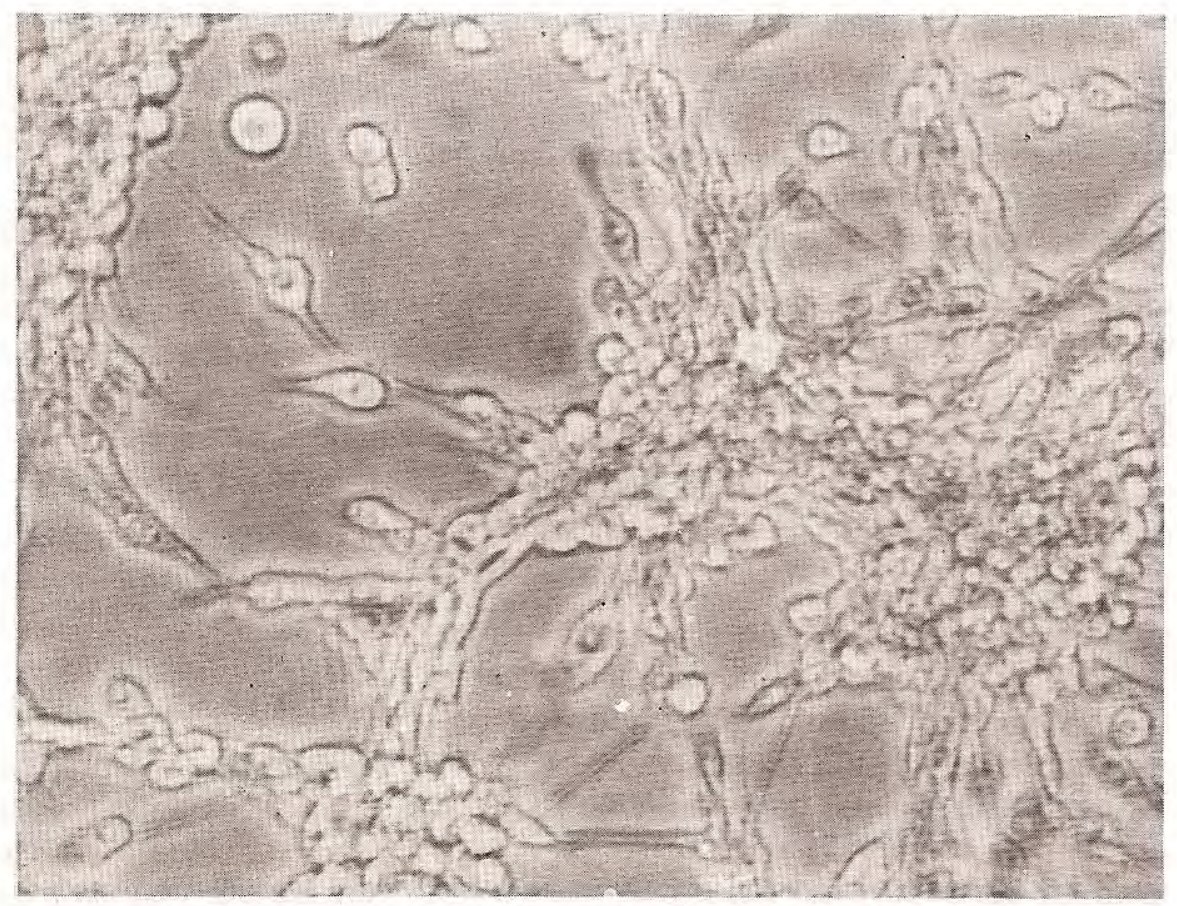




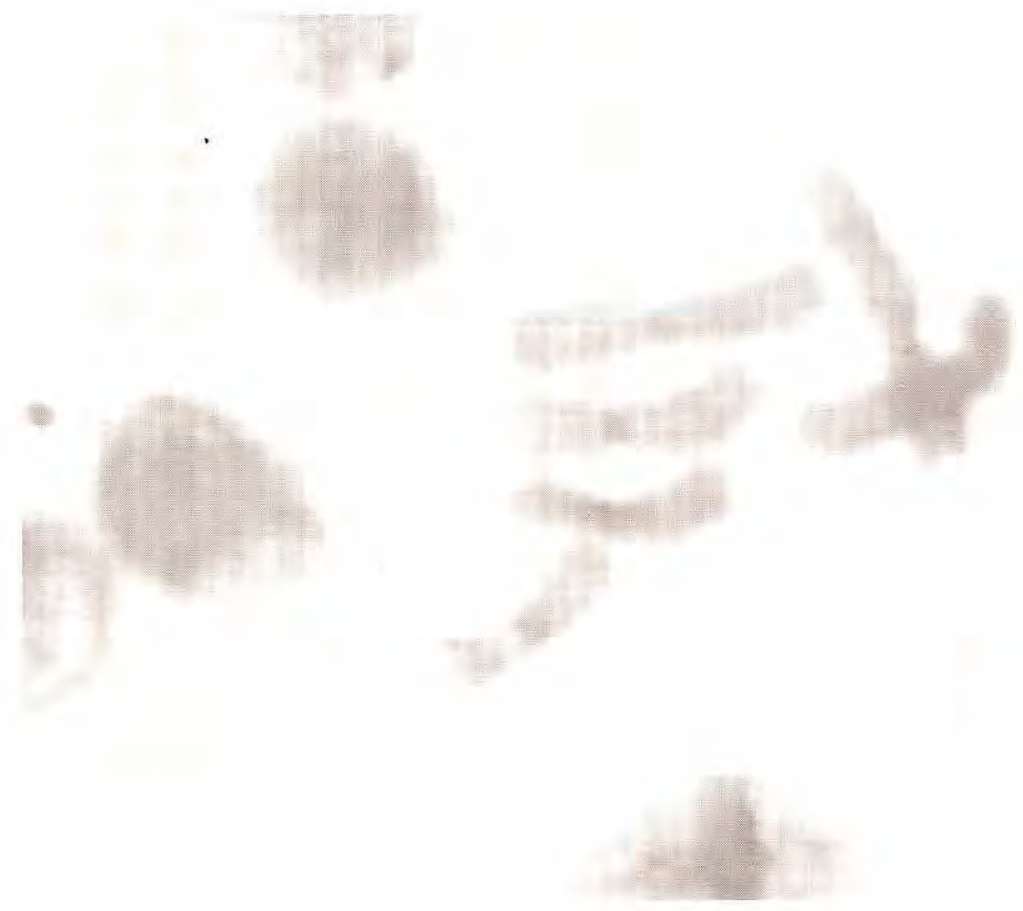

Figura 4. Cariotipo obtenido a partir de de cultivos celulares de Ae. taeniorhynchus, patrón de bandas $\mathrm{C}$. y 2 bandas para MPI. Estos resultados también correspondieron a las muestras de pupas corridas simultáneamente con los cultivos celulares de la especie. En la tabla 1 se muestran los valores promedios de las movilidades relativas de cada uno de los sistemas isoenzimáticos de la línea celular LSB-AT0793, tomando como patrón el clon C6/36 y comparándolos también con los cultivos celulares de An. albimanus. Los diagramas de los perfiles isoenzimáticos para cada uno de los sistemas se muestran en la figura 7.

\section{Discusión}

En los primeros seis subcultivos de $A e$. taeniorhynchus, el rango de división y crecimiento celular fue lento, a pesar de que se usaron concentraciones relativamente altas de siembras, en proporciones de 1:2; esta situación se explica porque las células necesitaron un período de adaptación a las nuevas condiciones ambientales, en cierta forma, diferentes a las del organismo, tales como: medio de cultivo, $\mathrm{pH}$, presión osmótica y temperatura. Sin embargo, no es una situación aislada, pues se registra también en algunos cultivos celulares de insectos que han sido establecidos (22). Posterior a esta etapa, cuya duración fue de 30 días, se presentó un período de intensa proliferación celular, con altos índices mitóticos en sucesivos pases la cual vino a ser interrumpido por una fase crítica, en el subcultivo número 29 , en donde un gran porcentaje de células murieron; las que lograron superar este trance, por selección y transformación genética a través de varias generaciones de cultivo, entraron a la etapa de crecimiento continuo para establecer la línea.

Aunque la mayoría de las células en las monocapas confluentes de los cultivos fueron de tipo epitelioide, hubo aisladamente otras formas, gigantes e irregulares, debido a que éste es un cultivo mixto en donde el origen celular era de diversos tejidos en las etapas iniciales de los embriones explantados. Sin embargo, se ha notado que, por simple diferenciación morfológica, es difícil distinguir los cultivos celulares de mosquitos, pues en alguna especies del género Aedes las células tienden a ser de formas parecidas, aun con clones celulares establecidos como el C6/36 (28), originario de la línea celular de Ae. albopictus. 

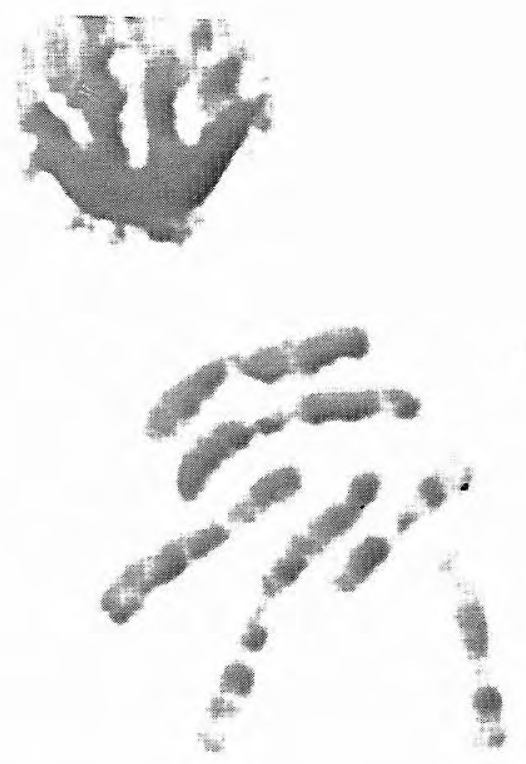

Figura 5. Cromosomas diploides de células de $A e$. taeniorhynchus, patrón de bandas $\mathrm{G}$.
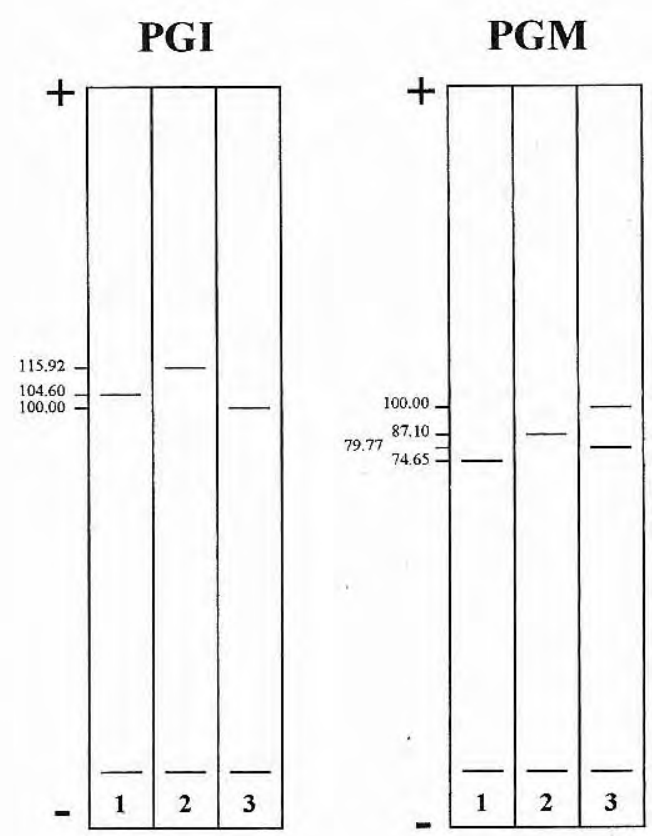
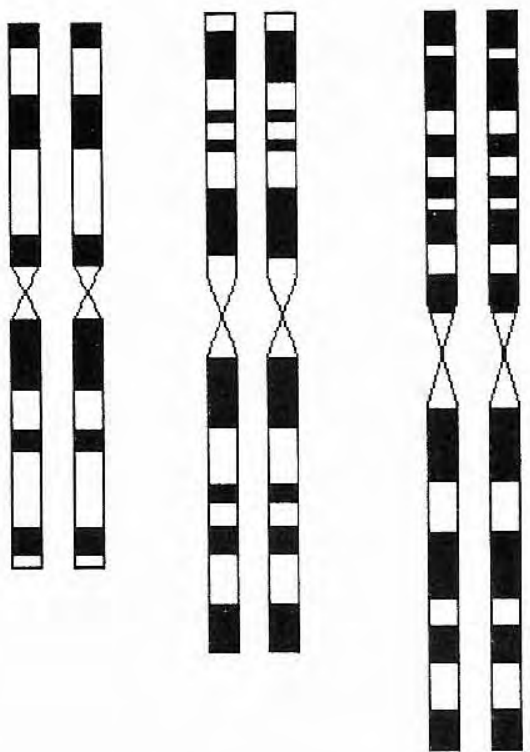

Figura 6. Representación esquemática del cariotipo de Ae. taeniorhynchus, con patrón fr bandas $\mathrm{G}$.
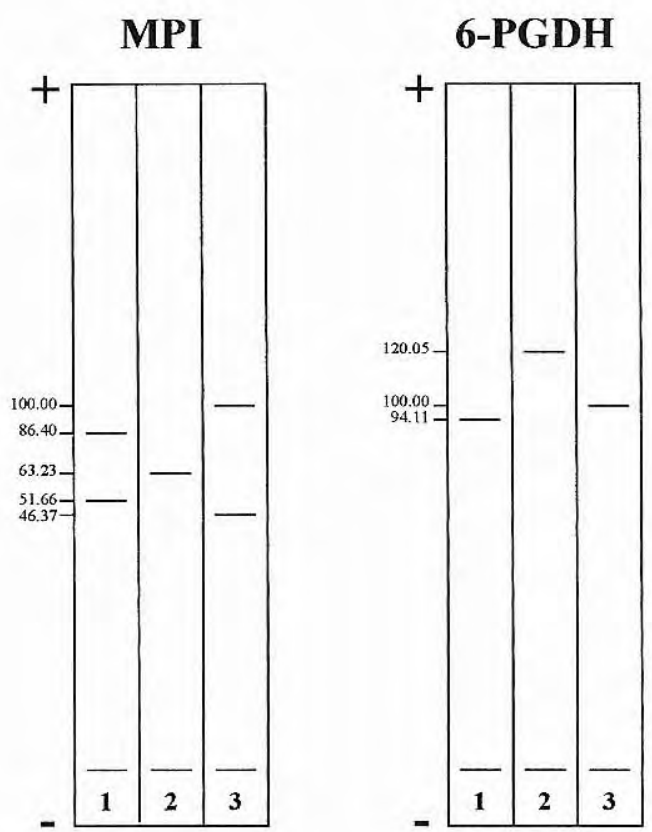

1: Ae. taeniorhynchus

2: An. albimanus

3: $\mathrm{C6} / 36$

Figura 7. Diagramas de los perfiles isoenzimáticos de la línea celular LSB-0793, en relación con el patrón C6/36 y con cultivos celulares de An. albimanus. 
Tabla 1. Promedio de las migraciones relativas de los fenotipos isoenzimáticos de los cultivos celulares de Ae. taeniorhynchus, en relación con el patrón C6/36 y con cultivos celulares de An. albimanus.

\begin{tabular}{|c|c|c|c|}
\hline SISTCMAS & LSB-AT0793 & LSB-AA-695BB $^{*}$ & C6/36 \\
\hline PGM & 74.65 & 87.10 & 100 \\
& & & 79.77 \\
\hline PGI & 104.60 & 115.92 & 100 \\
\hline MPI & 51.66 & 63.23 & 100 \\
& 86.40 & & 46.37 \\
\hline 6-PGDH & 94.11 & 120.05 & 100 \\
\hline
\end{tabular}

LSB-AA-695BB = Cultivos celulares de Anopheles albimants

En el presente estudio se establecieron los patrones de bandas C y G para esta especie, además del reconocimiento del cariotipo (13), lo que contribuye a distinguir cariológicamente a Ae. taeniorhynchus de otras especies del género. Sin lugar a dudas, una de las ventajas que ofrecen los cultivos celulares, desde el punto de vista citogénetico, es la relativa facilidad de manipulación y la efectividad de los pretrata-mientos que, en muchos casos, se dificulta al trabajar con el material in vivo. Sin embargo, como desventaja notamos la imposibilidad de utilizar las características intraespecíficas en cultivos celulares, por ejemplo, marcadores sexuales, como bandas intercalares para diferenciar el macho de la hembra; a pesar de que se presentaron, no fue una situación uniforme por la heterogenidad sexual de los tejidos embrionarios explantados, al iniciar el proceso para obtener la línea celular; en cambio, cuando Motara y Rai en 1978 trabajaron con preparaciones cromosómicas obtenidas a partir de tejidos germinales de pupas, en el estudio de bandas $C$ para algunas especies del género Aedes, se pudo nítidamente diferenciar el sexo de cada uno de los organismos, en donde los machos presentaron en el cromosoma 1, una banda intercalar y las hembras dos bandas (24).

Los patrones electroforéticos, utilizando la técnica de acetato de celulosa como sustrato, permitió determinar los perfiles isoenzimáticos de la línea celular con base en cuatro sistemas diferentes. Los resultados se compararon con las corridas de las muestras de pupas de la especie, que resultaron ser idénticas para todos los casos, lo que confirma el hecho de que los cultivos celulares continúan siendo representativos de los tejidos originarios de Ae. taeniorhynchus. También, en este trabajo se compararon las líneas celulares de Ae. taeniorhynchus y $A n$. albimanus con el patrón $\mathrm{C} 6 / 36$, siendo diferentes y peculiares los resultados para cada una de ellas, lo que permitió descartar contaminación de la presente línea con otras similares.

\section{Agradecimientos}

A COLCIENCIAS, la Universidad de La Salle y al Instituto Nacional de Salud de Colombia por la financiación del presente trabajo.

A los Hermanos Hernando Sebá López y Luis Humberto Bolívar R., rector y vicerrector académico de la Universidad de La Salle, respectivamente, por el apoyo brindado.

A los doctores Antonio Bermúdez y Cecilia Crane del Laboratorio de Genética del INS, por la colaboración en la toma y procesamiento de las microfotografías de los cromosomas.

Al doctor Hernán Hurtado, coordinador de investigaciones del Laboratorio de Neurobiología por la ayuda y colaboración brindada en las tomas microfotográficas de los cultivos celulares.

\section{Referencias}

1. Morales A, Ferro C, Isaza C, Cura E. Encuesta sobre artrópodos de interés médico en La Guajira, Colombia, Sur América. Biomédica 1987;7: 87-94.

2. Ministerio de Salud de Colombia-INS. Informe quincenal de casos y brotes de enfermedades. $I Q C B$ 1995;1(3/4):9-28.

3. Harrison RG. Observations on the living developing nerve fiber. Proc Soc Exp Biol Med 1907;4:140-143.

4. Carrel A. On the permanent life of tissues outside the organism. J Exp Med 1912;15:516-28.

5. Freshney RI. Culture of animal cells. A manual of basic techniques. Second edition. USA: John Wiley \& sons, Inc., 1987:397.

6. Igarashi Al. Mosquito cell culture and study of arthropod-borne togaviruses. Ad Virus Res 1985;30:21-42

7. Ball GH. Prolonged contraction of mosquito digestive tract in vitro with partial development of oocysts of Plasmodium relictum. Exp Parasitol 1954;3:358-67. 
8. Beckel WE. Maintenance of adult mosquito tissue in a culture. Nature (London) 1956;177:534.

9. Kitamura S. The in vitro cultivation of tissues from the mosquito Culex pipiens var. molestus. II. A improved culture medium useful for ovarian tissue culture. Kobe $J$ Med Sci 1965;11:315-433.

10. Grace TDC. Establishment of a line of mosquito (Aedes aegypti L.) cells grown in vitro. Nature (London) 1966;211:366-7.

11. Hink WF. The 1979 compilation of invertebrate cell line and culture media. In: Kurstak E, Maramorosch K, Dubendorfer A, editors. Invertebrate systems in vitro. Amsterdam: Elsevier North-Holland Biochemical Press, 1980:553-78.

12. Mitsuhashi $\mathrm{J}$. Establishment and some characteristics of a continuous cell line derived from fat body of the cabbage armyworm (Lepidoptera, Noctuidae). Dev Growth Differ 1981;23: 63-72.

13. Bello FJ, Boshell J, Rey G, Morales A, Olano VA. Initiation of primary cell cultures from embryos of the mosquitoes Anopheles albimanus arid Aedes taeniorhynchus (Diptera: Culicidae). Mem Inst Oswaldo Cruz 1995;90(4): 547-51.

14. Grace TDC. Development of insect cell cultures. In: Maramorosch K, Matsuhashi J, editors. Invertebrate cell culture, applications. New York: Academic Press, 1982: 1-8.

15. Kuno G, Gubler DJ, Vélez M, Oliver A. Comparative sensitivity of three mosquito cell lines for isolation of dengue viruses. Bull WHO 1985;63:279-86.

16. Lee SH, Hou RF. Establishment of a cell line derived from embryos of the iamondback moth, Plutella xylostella (L). J Invertebr Pathol 1992;59:174-7.

17. Maramorosch K. Biotechnology in invertebrate pathology and cell culture. San Diego: Academic Press, 1987: 511.

18. Sieburth PH, Maruniak JE. Growth characteristics of a continuous cell line from the velvetbeau caterpillar,
Anticarsia gemmatalis Hubner (Lepidoptera: Noctuidae). In Vitro Cell Dev Biol 1988;24:195-8.

19. Mitsuhashi J, Maramorosch K. Leafhoper tissue culture: embryonic, nymphal and imaginal tissue from aseptic insects. Contrib Boyce Thompson Inst 1964;22: 43560.

20. Varma MGR, Pudney M. The growth and serial passage of cell line from Aedes aegypti $(\mathrm{L})$ larvae in different media. J Med Entomol 1969;6:432-9.

21. Cahoon BE, Hardy JL, Reeves WC. Initiation and characterization of a diploid cell line from larval tissues of Aedes dorsalis (Meigen). In vitro Cell Dev Biol 1978; 14:255-60.

22. Pant U, Dhanda V, Aragade SP, Banderjee K. Establishment of three cell lines from the embryonic tissue of Cimex hemipterus (F.) (Hemiptera: Cimicidae). In Vitro Cell Dev Biol 1988;24:1201-3.

23. Schneider I. Preparation and maintenance of arthropod cell culture: diptera, with emphasis on mosquitoes. In: Yunker CE. Arboviruses in arthropod cells in vitro, vol. 1. Boca Ratón, FL: CRC, 1987:25.

24. Motara MA, Rai KS. Giemsa C-banding patterns in Aedes (Stegomyia) mosquitoes. Chromosoma 1978;70: 51-8.

25. Marchi A, Mezzanote R, Ferruci L. Characterization of the metaphase chromosomes in Anopheles stephensi (Liston, 1901) by Q-G and C-banding. Cytologia 1980;45:549-53.

26. Brown SE, Knudson DL. Characterization of invertebrate cell lines. III. Isozyme analyses employing celulose acetate electrophoresis. In Vitro Cell Dev Biol 1980; 16(10): 829-32.

27. Bello FJ, Olano VA, Morales A, Cassaleth E, Giraldo L, Hernández C. Establecimiento y mantenimiento de una colonia de Aedes taeniorhynchus, Wiedemann, 1821 (Diptera: Culicidae) cepa Barranquilla, Colombia. Biomédica 1994;14:69-76.

28. Oelofsen MJ, Gericke A, Smith MS, De K van der Linde TC. Establishment and characterization of a cell line from the mosquito Culex (Culex) theileri (Diptera: Culicidae) and its susceptibility to infection with arboviruses. J Med Entomol 1990;27:939-44. 